\title{
Evaluation of Soil Water Management Difference in Mango Orchards between Thailand and Japan
}

\author{
Kozue Yuge $^{1^{*}}$, Eriko Yasunaga ${ }^{2}$, Shinji Fukuda ${ }^{1}$, Wolfram Spreer ${ }^{3}$, Vicha Sardsud ${ }^{4}$, \\ Wanwarang Pattanopo ${ }^{5}$
}

${ }^{1}$ Faculty of Agriculture, Kyushu University, Fukuoka, Japan; ${ }^{2}$ Institute for Sustainable Agro-Ecosystem Services, Graduate School of Agricultural and Life Sciences, The University of Tokyo, Tokyo, Japan; ${ }^{3}$ Science and Technology Research Institute, Chiang Mai University, Chiang Mai, Thailand; ${ }^{4}$ School of Agro-Industry, Mae Fah Luang University, Chiang Rai, Thailand; ${ }^{5}$ Postharvest Technology Institute, Chiang Mai University, Chiang Mai, Thailand.

Email: *yuge@bpes.kyushu-u.ac.jp

Received October $12^{\text {th }}, 2012$; revised November $20^{\text {th }}, 2012$; accepted December $24^{\text {th }}, 2012$

\begin{abstract}
The objective of this study is to evaluate the difference of the soil water management in mango orchards between the varieties of "Irwin" in Japan and "Nam Dok Mai" in Thailand. Field observations were conducted in mango orchards in Okinawa, Japan and Phrao, Thailand to clarify the water management practices. Measurement of the hourly soil water content in Phrao indicated that the irrigation was scarce and the volumetric water content in the soil was maintained almost constant. in the flowering season. This can be the farmers' practice for flower induction. After the flowering season, irrigation was frequent in order to produce the large fruit. In the harvest season, the soil water content was relatively high because of frequent irrigation and rainfall. In Okinawa, the volumetric water content was maintained at the same level in a relatively deep layer. The result at the $5 \mathrm{~cm}$ depth indicated that the farmer carefully controlled the soil water content. In the flowering season, the soil water content was relatively low. While the orchard was managed empirically, the volumetric water content near the soil surface was maintained over $25 \%$ during the harvest season. This result indicates that the farmer performed the good soil water management to enhance mango fruit quality even without technical measurement. A numerical model describing the soil water and heat transfers was introduced to predict the farmer's empirical soil water management in Okinawa. Using the meteorological data in March 2010, the irrigation regime was predicted using the simulated soil water content. In the flowering season, the farmer irrigated when the soil surface water content reached $14 \%$. Based on this criterion for the empirical soil water management, the simulation result indicated that the farmer irrigated four times in this period. The numerical model presented here can be useful for evaluating the differences in water management practices of local farmers.
\end{abstract}

Keywords: Irrigation Regime; Soil Water and Heat Transfer; Numerical Model; Yield and Quality of Mango Fruit

\section{Introduction}

Mango (Mangifera indica L.) is one of most important crops in tropical and subtropical regions, including southeastern Asia and Central and South America. Thailand is one of the most important mango producers and exporters in the world. There are many varieties of the mango fruit, including "Nam Dok Mai", "Maha Chanok", "Chok Anan", and so on. As "Nam Dok Mai" is produced for export to Japan and European countries, the farmer is expected to manage the field condition to ensure the quality and safety of fruits. In Japan, the demand for mango fruit as a luxury gift has accelerated its production. Okinawa, an island located southwest of Japan, is the main producer of mango fruit in Japan, and

"Corresponding author.
"Irwin" is the major variety produced. Most farmers conduct the empirical water management carefully to enhance the yield and quality of mango fruit in Okinawa.

Soil water management is one of the most important factors for the development, yield, and quality of the mango fruit. The effects of water management on the yield, development, and quality of the mango fruit have been researched. Azevedo et al. (2003) [1] determined the daily water requirements of a mango orchard comprised of the "Tommy Atkins" variety. Gonzalez et al. (2004) [2] indicated that pre-flowering irrigation increased the overall photosynthetic activity of the mango tree of "Kensington Pride" variety at the time of flowering and affected the yield of the mango fruit. Spreer et al. $(2007,2009)[3,4]$ clarified the difference of the yield and quality of mango fruit of "Chok Anan" variety under 
various irrigation regimes in Thailand. Teixeira et al. (2008) [5] introduced the eddy covariance technique to estimate the actual evapotranspiration in the mango orchard of "Tommy Atkins" and assessed the daily and seasonal mango evapotranspiration in the different rainfall regimes. Silva et al. (2009) [6] conducted field observation to determine the evapotranspiration (ET) and water use efficiency (WUE) in mango orchard of "Tommy Atkins", and clarified that ET and WUE were affected by soil water availability.

The results of these studies indicate that the soil water management is one of the most important factors for healthy breeding and enhancing the yield and quality of mango fruit. To improve the growth, yield and quality of mango fruit, the soil water condition should be carefully managed, considering the variety of mango fruit, weather condition, and so on. However the soil water management practices for different varieties of the mango fruit has not yet been evaluated. In particular, the soil water management conditions of the lucrative varieties of mango fruit including "Nam Dok Mai" and "Irwin" have not been clarified. Since better breeding strategies for mango fruit should be developed together with appropriate management practices for its production, it is very important to clarify the farmers' empirical soil water management for the lucrative varieties.

The objective of this study is to evaluate difference of the soil water management in mango orchards between the varieties of "Irwin" in Japan and "Nam Dok Mai" in Thailand. Field observations were conducted in mango orchards in Japan and Thailand to clarify the water management practices. A numerical model describing the soil water and heat transfers was introduced to predict the farmers' empirical soil water management.

\section{Study Site}

Field observation was conducted in mango orchards in Phrao and Okinawa. Phrao is located in north Thailand, $80 \mathrm{~km}$ from Chiang Mai. Okinawa is an island located southwest of Japan, $1600 \mathrm{~km}$ from Tokyo, and classified as a subtropical zone. "Nan Dok Mai" and "Irwin" are produced in Phrao and Okinawa, respectively. Figure 1 shows the monthly precipitation in Chiang Mai and Okinawa in 2009. Chiang Mai has a dry season and a rainy season, as shown in this figure. In Okinawa, precipitation is relatively high throughout the year, except for January and February. The monthly mean air temperature in Chiang Mai and Okinawa are shown in Figure 2. From June to September, the temperature is almost the same in both areas, but from October to May, the temperature in Okinawa is lower. Specifically, in the winter season (December to March), the temperature drops below 20 degrees in Okinawa.

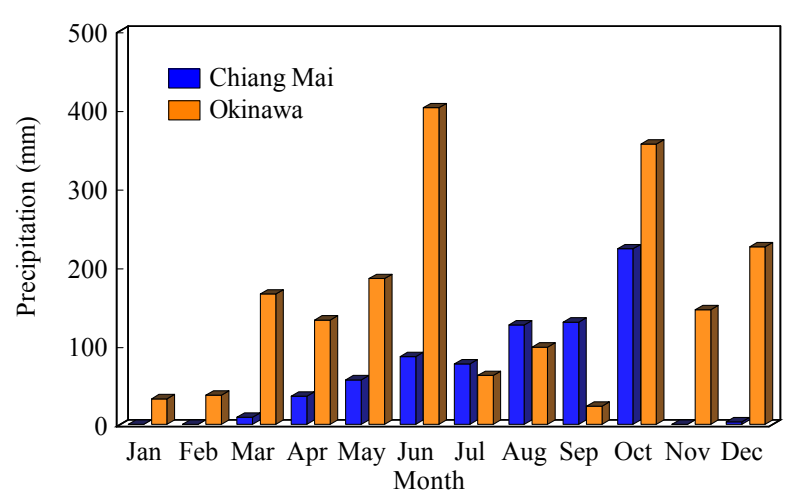

Figure 1. Monthly changes of the precipitation in Chiang Mai and Okinawa in 2009.

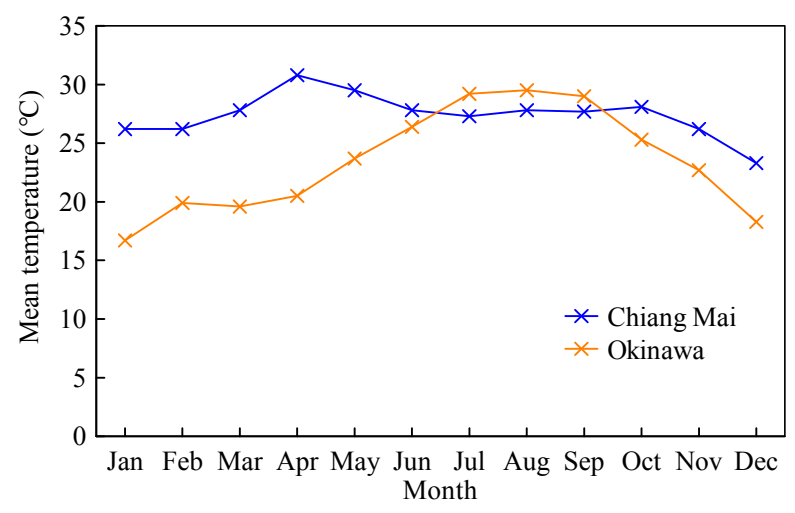

Figure 2. Monthly changes of the mean air temperature in Chiang Mai and Okinawa in 2009.

Whereas the mango fruit is produced at open fields in Phrao; in Okinawa, a plastic greenhouse culture has been introduced. The mango fruit grown in Phrao is for export, and the farmer is expected to manage the field condition carefully to retain safety and quality. In Okinawa, the mango fruit is produced to be consumed as a luxury gift in Japan. Farmers there carefully manage the field conditions, including the soil water content, air humidity, and temperature, to ensure the fruit quality.

\section{Field Observation}

Field observations were conducted to clarify the difference of the soil water management. Soil sampling was conducted to measure the soil water retentivity and hydraulic conductivity in Phrao and Okinawa. Soil water retention curve was obtained by suction plate method and centrifuge method. Unsaturated hydraulic conductivity was measured by One-step method.

The soil water content was measured at the depth of 5 $\mathrm{cm}, 15 \mathrm{~cm}$ and $25 \mathrm{~cm}$ using soil moisture sensors $\left(\mathrm{ECH}_{2} \mathrm{O}-10\right.$ and $\mathrm{ECH}_{2} \mathrm{O}-\mathrm{TE}$, Decagon) in both locations. In addition, solar radiation, air temperature, and humidity were measured in the Okinawa field. 


\section{Numerical Model to Predict the Irrigation Regimes}

\subsection{Governing Equations of Soil Water and Heat Transfer}

Using the data obtained in Okinawa, a two-dimensional soil water and heat transfer model was introduced to simulate the soil water content and to predict the irrigation regime in the mango field. The governing equation describing soil water and heat transfers can be described as follows:

$$
\begin{aligned}
\frac{\partial \theta}{\partial t}= & \frac{\partial}{\partial x}\left(D_{w} \frac{\partial \theta}{\partial x}\right)+\frac{\partial}{\partial z}\left(D_{w} \frac{\partial \theta}{\partial z}\right) \\
& +\frac{\partial}{\partial x}\left(D_{T} \frac{\partial T}{\partial x}\right)+\frac{\partial}{\partial z}\left(D_{T} \frac{\partial T}{\partial z}\right)+\frac{\partial K}{\partial x}+S \\
C_{v} \frac{\partial T}{\partial t} & =\frac{\partial}{\partial x}\left(\lambda \frac{\partial T}{\partial x}\right)+\frac{\partial}{\partial z}\left(\lambda \frac{\partial T}{\partial z}\right) \\
& +L \rho_{w}\left\{\frac{\partial}{\partial x}\left(D_{w v} \frac{\partial \theta}{\partial x}\right)+\frac{\partial}{\partial z}\left(D_{w v} \frac{\partial \theta}{\partial z}\right)\right\}
\end{aligned}
$$

where $C_{v}$ is the volumetric heat capacity $\left(\mathrm{J} \cdot \mathrm{m}^{-3} \cdot{ }^{\circ} \mathrm{C}^{-1}\right), D_{\mathrm{w}}$ is the isothermal water diffusivity $\left(\mathrm{m}^{2} \cdot \mathrm{s}^{-1}\right), D_{\mathrm{w} v}$ is the isothermal vapor diffusivity $\left(\mathrm{m}^{2} \cdot \mathrm{s}^{-1}\right), D_{T}$ is the thermal water diffusivity $\left(\mathrm{m}^{2} \cdot \mathrm{s}^{-1} \cdot{ }^{\circ} \mathrm{C}^{-1}\right), K$ is the hydraulic conductivity $\left(\mathrm{m} \cdot \mathrm{s}^{-1}\right), L$ is the latent heat of water vaporization $\left(\mathrm{J} \cdot \mathrm{kg}^{-1}\right), S$ is the $\operatorname{sink}\left(\mathrm{m}^{3} \cdot \mathrm{m}^{-3} \cdot \mathrm{s}^{-1}\right), T$ is the soil temperature $\left({ }^{\circ} \mathrm{C}\right), t$ is the time $(\mathrm{s}), \lambda$ is the thermal conductivity $\left(\mathrm{W} \cdot \mathrm{m}^{-1} \cdot{ }^{\circ} \mathrm{C}^{-1}\right), \rho_{w}$ is the water density $\left(\mathrm{kg} \cdot \mathrm{m}^{-3}\right)$, and $\theta$ is the volumetric soil water content $\left(\mathrm{m}^{3} \cdot \mathrm{m}^{-3}\right)$.

\subsection{Boundary Conditions}

The energy budget on the soil surface at the mango field can be described as follows:

$$
R_{n}=E+H+G
$$

where $R_{n}$ is the net radiation $\left(\mathrm{W} \cdot \mathrm{m}^{-2}\right), E$ is the latent heat flux $\left(\mathrm{W} \cdot \mathrm{m}^{-2}\right), H$ is the sensible heat flux $\left(\mathrm{W} \cdot \mathrm{m}^{-2}\right)$, and $G$ is the ground heat flux $\left(\mathrm{W} \cdot \mathrm{m}^{-2}\right)$.

The net radiation $R_{n}$ can be estimated using the following equation considering the shortwave and longwave radiation balance.

$$
R_{n}=(1-\alpha) R_{s}+L_{c}+L_{s k y}-L_{\text {soil }}
$$

where $R_{S}$ is the shortwave radiation on the soil surface $\left(\mathrm{W} \cdot \mathrm{m}^{-2}\right), L_{c}$ is the longwave radiation from the crop body $\left(\mathrm{W} \cdot \mathrm{m}^{-2}\right), L_{s k y}$ is the longwave radiation from the sky $\left(\mathrm{W} \cdot \mathrm{m}^{-2}\right), L_{\text {soil }}$ is the longwave radiation from the soil surface $\left(\mathrm{W} \cdot \mathrm{m}^{-2}\right)$, and $\alpha$ is the albedo.

The sensible heat flux and the latent heat flux on the soil surface can be estimated as follows:

$$
\begin{gathered}
H=c_{p} \rho \frac{T_{s}-T_{a}}{r} \\
L E=\frac{c_{p} \rho}{\gamma} \frac{e_{s}-e_{a}}{r}
\end{gathered}
$$

where $T_{s}$ is the soil surface temperature $\left({ }^{\circ} \mathrm{C}\right), c_{p}$ is the specific heat of the air $\left(\mathrm{J} \cdot \mathrm{kg}^{-1} \cdot{ }^{\circ} \mathrm{C}^{-1}\right), e_{a}$ is the air vapor pressure $(\mathrm{hPa}), e_{s}$ is the vapor pressure on the soil surface $(\mathrm{hPa}), r_{a}$ is the diffusion resistance $\left(\mathrm{s} \cdot \mathrm{m}^{-1}\right), \gamma$ is the psychrometer constant $\left(\mathrm{hPa} \cdot{ }^{\circ} \mathrm{C}^{-1}\right)$, and $\rho$ is the air density $\left(\mathrm{kg} \cdot \mathrm{m}^{-3}\right)$.

The diffusion resistance can be calculated using the following equation (Chamberlain, 1968) [7]:

$$
r_{a}=\frac{1}{\kappa u_{*}} \ln \left(\frac{z}{z_{0}}\right)+a\left(\frac{u_{*} \xi}{v}\right)^{b}\left(\frac{v}{D_{v}}\right)^{c}
$$

where $D_{v}$ is the molecular diffusion coefficient $\left(\mathrm{m}^{2} \cdot \mathrm{s}^{-1}\right)$, $u_{*}$ is the friction velocity $\left(\mathrm{m} \cdot \mathrm{s}^{-1}\right), z$ is the height of the measurement of the wind velocity $(\mathrm{m}), z_{0}$ is the roughness length $(\mathrm{m}), \xi$ is the effective soil surface roughness $(\mathrm{m})$, and $v$ is the kinematic viscosity of air $\left(\mathrm{m}^{2} \cdot \mathrm{s}^{-1}\right)$. The constants $a, b$, and $c$ are reported as $0.52,0.45$, and 0.8 , respectively, by Chamberlain (1968).

Using energy balance estimated by Equations (3)-(7), boundary conditions on the soil surface can be described as follows:

$$
\begin{gathered}
E=L \rho_{w}\left(-D_{w} \frac{\partial \theta}{\partial z}-D_{T} \frac{\partial T}{\partial z}-K\right) \\
G=-\lambda \frac{\partial T}{\partial z}-L \rho_{w} D_{w v} \frac{\partial \theta}{\partial z}
\end{gathered}
$$

Figure 3 shows the schematic view of the numerical model describing water and heat transfers in the soil. To solve the two-dimensional transfers of water and heat, the finite-differential method was used (Yuge et al., 2005) [8].

Using the numerical model as well as the meteorological data in Okinawa in 2010, the volumetric water content on the soil surface was simulated and the irrigation regime was predicted. It was not possible to simulate the irrigation regime in Phrao due to insufficient data caused by technical problems in the field.

\section{Results and Discussion}

Figure 4 shows the soil water retention curve in Phrao and Okinawa. From this figure, the soil water retentivity in Okinawa is high compared with the data in Phrao. The difference of the saturated volumetric water content between Phrao and the Okinawa is about 20\%.

The hydraulic conductivities in Phrao and Okinawa are shown in Figure 5, from which the difference of the hydraulic conductivity in these fields can be evaluated. 


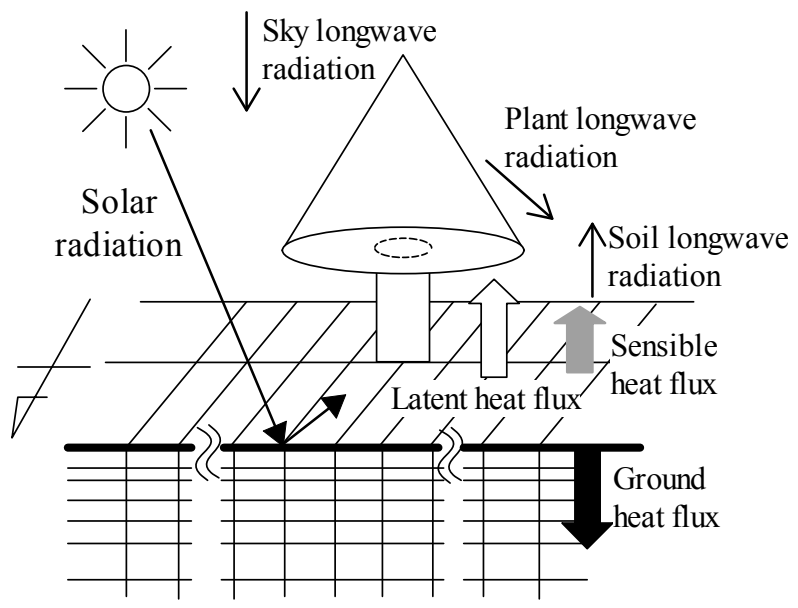

Figure 3. Schematic view of numerical model describing water and heat transfers in the soil.

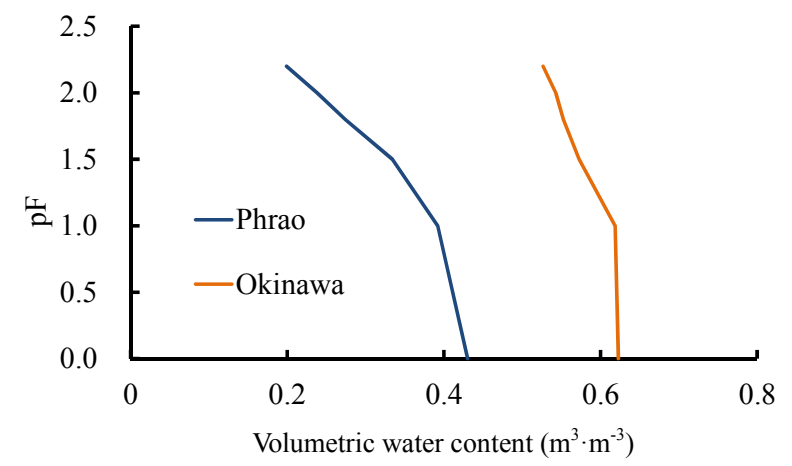

Figure 4. Soil water retention curve in Phrao and Okinawa.

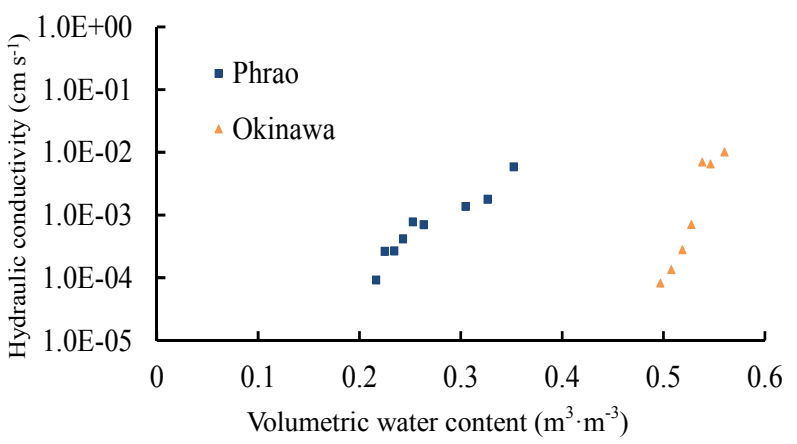

Figure 5. Unsaturated hydraulic conductivity in Phrao and Okinawa.

The change of the hydraulic conductivities in Okinawa is drastic compared with the volumetric water content of Phrao.

Figure 6 shows the hourly change of the soil water content in Phrao from mid-September 2009 to July 2010. Soil water condition was maintained high from September to early November because it was rainy season as sown in Figure 1. In the flowering season after the rainy season, water supply was scarce and the volumetric water content in the soil was maintained almost constant. This

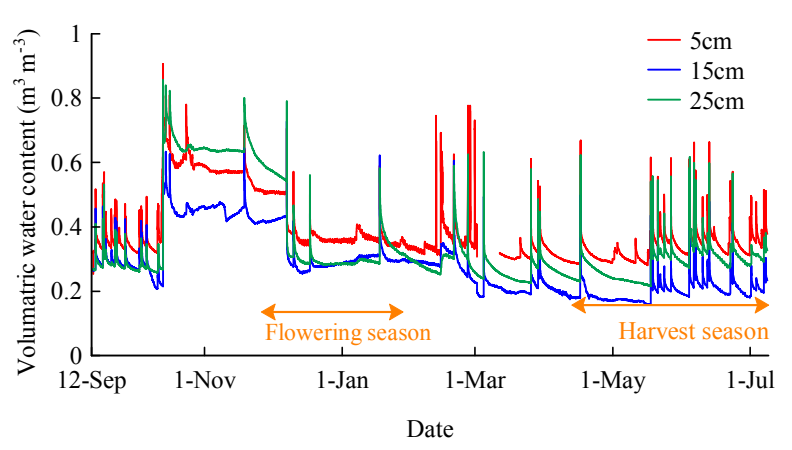

Figure 6. Hourly change of the soil water content in Phrao.

water management to keep lower soil water content may be the farmers' practice for flower induction. After the flowering season, irrigation was frequent to produce the large fruit. In the harvest season, the soil water content was relatively high because of frequent irrigation and rainfall.

Figure 7 shows the changes of the volumetric water content from late March to December 2009 in Okinawa. At the depths of $15 \mathrm{~cm}$ and $25 \mathrm{~cm}$, the volumetric water content was maintained at the same level. The result at the $5 \mathrm{~cm}$ depth indicates that the farmer carefully controlled the soil water content. In the flowering season, the soil water content was relatively low. During the harvest season, the volumetric water content near the soil surface was maintained over $25 \%$. This result indicates that the farmer empirically irrigated in order to enhance the mango fruit quality.

Comparing Figures 6 and 7, the fluctuation of the soil water content in Phrao is larger than that in Okinawa. In Okinawa, the mango fruit was grown in greenhouses and the farmer controlled the soil water condition carefully to produce high-quality fruit. In Phrao, the mango fruit was grown in an open field and management of the soil water content was affected by meteorological conditions. The soil water content in the flowering season in Okinawa was much lower, compared with the soil water content in Phrao.

Figure 8 depicts the hourly change of the volumetric water content simulated using the meteorological data in Okinawa in March 2010. In the flowering season, the farmer supplied the irrigation water when the soil surface water content reached $14 \%$. Based on this criterion for the empirical soil water management, it was found that the farmer irrigated four times in this period.

\section{Conclusions}

To evaluate the soil water management difference in mango orchards between Thailand and Japan, field observations were conducted in Phrao and Okinawa, respectively. Soil water retentivity in Okinawa was higher 


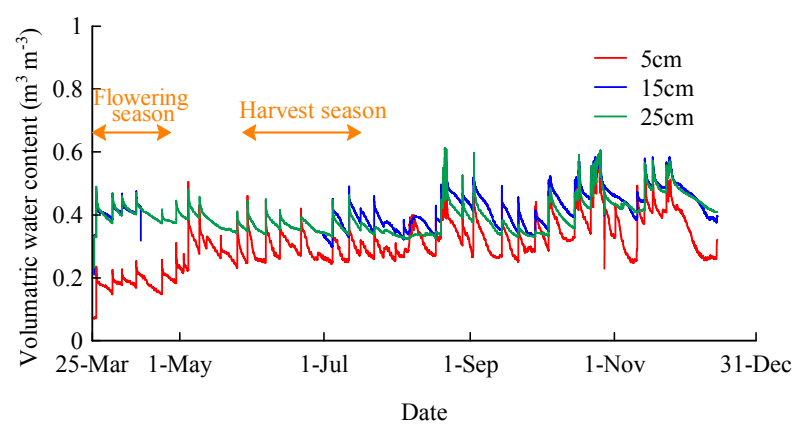

Figure 7. Hourly change of the soil water content in Okinawa.

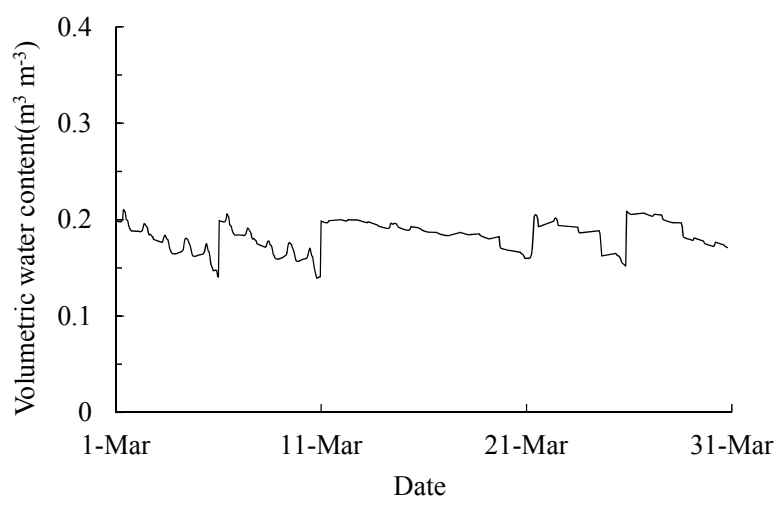

Figure 8. Hourly change of the volumetric water content simulated using the meteorological data in Okinawa in March 2010.

compared with Phrao. The hydraulic conductivity showed significant differences between Okinawa and Phrao. The difference of the soil water management was clarified by the measurements of the temporal changes of soil water content. The results indicated that the farmers changed the irrigation regime with the growth stages of mango fruit, which is in line with the changes in the importance of water supply with time as it was reported by Fukuda et al. (2012) [9]. The fluctuation of the soil water content in Phrao is larger than that in Okinawa. In Okinawa, the mango fruit was grown in greenhouses and the farmer carefully controlled the soil water condition to ensure the high-quality fruit. In Phrao, the mango fruit was grown in an open field and management of the soil water content was affected by meteorological conditions. The soil water content in the flowering season in Okinawa was much lower, compared with the soil water content in Phrao. This implies that the farmers in Okinawa manage soil water more precisely than the farmers in Phrao.

The two-dimensional soil water and heat transfer model successfully represented the farmer's empirical soil water management practice in Okinawa. The irrigation regime in Phrao can also be predicted when the meteorological data, including the solar radiation, air tem- perature and humidity, wind velocity, and precipitation, are collected. The numerical model introduced here is useful for irrigation scheduling. Its effectiveness in enhancing the yield and quality of mango fruit has to be tested under field conditions.

\section{Acknowledgements}

We express our deep appreciation to the staff of Chiang Mai University and the Tomigusuku branch office of JA (Japan Agricultural Cooperatives) Okinawa for their support.

\section{REFERENCES}

[1] P. V. Azevedo, B. B. Silva and V. P. R. Silva, "Water Requirements of Irrigated Mango Orchards in Northeast Brazil," Agricultural Water Management, Vol. 58, No. 3, 2003, pp. 241-254. doi:10.1016/S0378-3774(02)00083-5

[2] A. González, P. Lua and W. Müller, "Effect of Pre-Flowering Irrigation on Leaf Photosynthesis, Whole-Tree Water Use and Fruit Yield of Mango Trees Receiving Two Flowering Treatments," Scientia Horticulturae, Vol. 102, No. 2, 2004, pp. 189-211. doi:10.1016/j.scienta.2003.12.011

[3] W. Spreer, S. Ongprasert, M. Hegele, J. N. Wünsche and J. Müller, "Yield and Fruit Development in Mango (Mangifera indica L. cv. Chok Anan) under Different Irrigation Regimes," Agricultural Water Management, Vol. 96, No. 4, 2009, pp. 574-584. doi:10.1016/j.agwat.2008.09.020

[4] W. Spreer, M. Nagle, S. Neidhart, R. Carle, S. Ongprasert and J. Müller, "Effect of Regulated Deficit Irrigation and Partial Rootzone Drying on the Quality of Mango Fruits (Mangifera indica L., cv. 'Chok Anan'),' Agricultural Water Management, Vol. 88, No. 1-3, 2007, pp. 173-180. doi:10.1016/j.agwat.2006.10.012

[5] A. H. C. Teixeira, W. G. M. Bastiaanssen, M. S. B. Moura, J. M. Soares, M. D. Ahmad and M. G. Bos, "Energy and Water Balance Measurements for Water Productivity Analysis in Irrigated Mango Trees, Northeast Brazil," Agricultural and Forest Meteorology, Vo1. 48, No. 10,2008 , pp. 1524-1537.

doi:10.1016/j.agrformet.2008.05.004

[6] V. P. R. Silva, J. H. B. Cunha Campos and P. V. Azevedo, "Water-Use Efficiency and Evapotranspiration of Mango Orchard Grown in Northeastern Region of Brazil," Scientia Horticulturae, Vol.120, No. 4, 2009, pp. 467-472. doi:10.1016/j.agwat.2006.10.012

[7] A. C. Chamberlain, "Transport of Gases to and from Surface with Bluff and Wave-Like Roughness Elements," Quarterly Journal of the Royal Meteorological Society, Vol. 94, No. 401, 1968, pp. 318-332. doi:10.1002/qi.49709440108

[8] K. Yuge, M. Ito, Y. Nakano, M. Kuroda and T. Haraguchi, Soil Moisture and Temperature Changes Affected by Isolated Plant Shadow," Journal of Agricultural Meteorology, Vol. 60, No. 5, 2005, pp. 717-772.

[9] S. Fukuda, W. Spreer, E. Yasunaga, K. Yuge, V. Sardsud 
and J. Müller, "Random Forests Modelling for the Estimation of Mango (Mangifera indica L. cv. Chok Anan)

Fruit Yields under Different Irrigation Regimes," Agri- cultural Water Management, in Press. doi:10.1016/j.agwat.2012.07.003 